\title{
Fenologia do coqueiro na zona costeira de Pernambuco ${ }^{(1)}$
}

\author{
Isa Regina do Monte Leite ${ }^{(2)}$ e Carlos Ramirez Franco da Encarnação(2)
}

\begin{abstract}
Resumo - O objetivo do trabalho foi estudar a fenologia do coqueiro em duas cultivares (Anão-amarelo, Anão-verde) e um híbrido (PB 121), na Unidade de Execução de Pesquisa de Itapirema, Goiana, PE. Realizaram-se observações semanais das fases vegetativas e reprodutivas de cinco plantas de cada cultivar e do híbrido, durante o período janeiro/96 a janeiro/97. Dados do balanço hídrico foram utilizados para associar a fenologia às disponibilidades hídricas locais. A quantidade de graus-dia variou entre 266 graus-dia, na estação chuvosa, e 350 graus-dia, na estação seca. Determinou-se o quadrante predominante na emissão de inflorescência e a direção do vento. Estabeleceram-se os índices de fecundação das flores e produção dos frutos. A espécie em estudo é uma planta perenifólia. As cultivares e o híbrido produziram cerca de 11 folhas anualmente. Verificaram-se folhas mortas durante todo o período de observação. Houve floração durante todo o ano. As plantas emitem uma inflorescência/mês, ocasionalmente duas (Anão-amarelo e híbrido), no período seco. As cultivares têm o mesmo número de inflorescências emitidas, mas não o mesmo número de inflorescências desenvolvidas. A floração é do tipo cornucópia. Observaram-se frutos em diferentes estádios de desenvolvimento num mesmo espécime e cacho. A direção do vento, assim como o quadrante na emissão de inflorescências estabelecidos foi predominantemente o Sudeste. Houve diferenças significativas entre os tratamentos.
\end{abstract}

Termos para indexação: Cocos nucifera, disponibilidade hídrica, variação sazonal, periodicidade.

\section{Phenology of coconut palms on the Coastal Zone of Pernambuco, Brazil}

\begin{abstract}
The objective of the present work was to study the phenology of two coconut palm cultivars (yellow dwarf, green dwarf) and a hybrid (PB 121). The study was conducted at the Itapirema Research Unit, Goiana, PE, Brazil. Weekly observations were taken from the vegetative and reproductive phases of five plants of each one of the cultivars studied, during the period of January/96 through January/97. Data on the water balance were used to associate phenology and local water availability. The amount of degrees-day varied between 266 degrees-day, during the rainy season, and 350 degreesday, during the dry season. The predominant quadrant for the emission of the inflorescence as well as for the wind direction was determined. Also the indexes of flower fecundity and fruit production were established. The species studied is perennial. All three cultivars produced around 11 leaves yearly. Dead leaves were verified during the whole experiment period. Flowering occurred during the whole year. The plants produced one inflorescence/month, occasionally two (yellow dwarf, hybrid), during the dry period. The cultivars produced the same number of inflorescences, but not the same in development. The flowering is cornucopia type. Fruits under different development stages were observed in a same specimen and cluster. The wind direction, as well as the quadrant of inflorescence position established were predominantly Southeastern. There were significant differences among the treatments.
\end{abstract}

Index terms: Cocos nucifera, water availability, seasonal variation, periodicity.

\footnotetext{
(1) Aceito para publicação em 31 de maio de 2001.

Extraído da dissertação de mestrado apresentada pelo primeiro autor à Universidade Federal de Pernambuco (UFPE), Recife, PE. Parcialmente financiado pela Capes.

(2) UFPE, Dep. de Botânica, Av. Prof. Moraes Rego, s/nº, Cidade Universitária, CEP 50670-901 Recife, PE. E-mail: irleite@yahoo.com
}

\section{Introdução}

A fenologia de plantas perenes vem sendo utilizada no Brasil para ampliar os conhecimentos em silvicultura, medicina popular, melhoramento genético, agrometeorologia, ecologia, paisagismo, turismo, 
manejo correto de culturas e em outras áreas afins, assim como na preservação e planificação dos ecossistemas tropicais, em determinada região (Morellato et al., 1990). Estes estudos revelam que as fases vegetativa e reprodutiva estão associadas aos fatores climáticos, e verificou-se que a disponibilidade de água e a temperatura são fatores limitantes deste mecanismo no ciclo anual das plantas (Morellato et al., 1990).

Apesar da importância de seus resultados, no Nordeste do Brasil, a quantidade de trabalhos registrando a fenologia de culturas é muito limitada e genérica, notadamente, quando se trata da fenologia da família Palmae, e poucos são os citados em literatura, como, por exemplo, o de Belo (1989).

Literatura sobre fenologia de coqueiro foi encontrada em esparsas pesquisas abordando dados genéricos de algumas de suas fenofases sendo, estes trabalhos, direcionados à biologia floral (Alvim, 1966), à ecofisiologia (Murray, 1942), à fitotecnia (Queiroz et al., 1990), à taxonomia (Reitz, 1974) e à botânica econômica (Siqueira et al., 1992).

A fenologia é importante na nucicultura, como demonstradora das respostas às condições ambientais quantitativas do desenvolvimento do coqueiro, e, conseqüentemente, na sua produção.

O ritmo biológico da cultura é coordenado pelo hidroperiodismo e termoperiodismo, instáveis na região tropical, e deve ser associado à fenologia, para se obterem subsídios complementares ao melhoramento genético e sugerir manejo correto à cultura.

O objetivo deste trabalho foi estudar as fenofases vegetativas e reprodutivas do coqueiro em duas cultivares (Anão-amarelo, Anão-verde) e um híbrido (PB 121) e seus hidroperiodismo e termoperiodismo.

\section{Material e Métodos}

Os dados experimentais foram obtidos na Unidade de Execução de Pesquisa de Itapirema (UEP), pertencente à Empresa Pernambucana de Pesquisa Agropecuária (IPA), localizada na Zona da Mata de Pernambuco e nos tabuleiros costeiros, no Município de Goiana, PE, tendo como coordenadas latitude de $7^{\circ} 33^{\prime} 45^{\prime \prime} \mathrm{S}$, longitude de $35^{\circ} 0^{\prime} 0^{\prime \prime} \mathrm{W}$ e altitude de 14 m (Encarnação, 1979). A temperatura média anual é de $26^{\circ} \mathrm{C}$, e as precipitações anuais atingem $2.128 \mathrm{~mm}$. Com base na classificação de Thorntwaite \& Mather (1955), o tipo climático da região é Úmido
Megatérmico $\left(\mathrm{B}_{2} \mathrm{~S}_{2} \mathrm{~A}_{2}{ }^{\prime}\right)$. Os solos predominantes são o Podzólico Vermelho-Amarelo latossólico, Podzólico Hidromórfico, Latossolo Vermelho-Amarelo, e Areias Quartzosas distróficas (Empresa Pernambucana de Pesquisa Agropecuária, 1981).

Foram selecionadas, aleatoriamente, cinco plantas das cultivares: Anão-amarelo, Anão-verde e do híbrido PB 121, numa plantação homogênea, com espaçamento entre plantas de $10 \times 10 \mathrm{~m}$, em um coqueiral com 12 anos.

As observações fenológicas foram realizadas semanalmente, durante o período janeiro/96 a janeiro/97, conforme recomendações de Fournier (1974) e Falcão (1979). Foram realizadas 52 observações, posteriormente agrupadas de quatro em quatro, obtendo-se um total de 13 períodos, cada um com dados correspondentes a 28 dias, a partir da primeira observação. Foi considerado o intervalo de 28 dias, porque a partir deste intervalo houve mudanças diferenciadas no ciclo vegetativo e reprodutivo das cultivares.

$\mathrm{Na}$ avaliação das fases vegetativa e reprodutiva, levaram-se em consideração os seguintes critérios: emissão de folhas (quando do aparecimento do espigão); abertura das folhas (quando $50 \%$ da folha encontrava-se aberta); folhas mortas (quando apresentavam $100 \%$ de coloração marrom escura); total de inflorescências (número de inflorescências abertas e fechadas); inflorescências emitidas (consideradas quando do surgimento do eixo da espata); flor feminina emitida (número total de flores femininas não fecundadas); frutos imaturos (a partir da observação do intumescimento do cálice até a mudança de coloração), e frutos em desenvolvimento (os que apresentavam predominância de crescimento do sentido vertical sobre o horizontal, o que se contrapõe à fase de maturação dos frutos).

O hidroperíodo (balanço hídrico) foi observado conforme Ometto (1987), aliando o comportamento das plantas aos resultados do balanço hídrico semanal, por meio de dados coletados na Estação Meteorológica do IPA, seguindo o método de Thorntwaite \& Mather (1955).

O termoperíodo foi empregado com base no método de determinação de produtividade ótima, preconizado por Maniero (1980) e fundamentado na aplicação de graus-dia (GD), computados através do modelo matemático de Nova et al. (1972):

$\mathrm{GD}=(\mathrm{Tn}-\mathrm{Tb})+(\mathrm{Tx}-\mathrm{Tn} / 2) \mathrm{N}$,

onde:

GD, representa graus-dia (unidades térmicas); $\mathrm{Tn}$, a temperatura mínima diária do $\operatorname{ar}\left({ }^{\circ} \mathrm{C}\right)$; Tx, a temperatura máxima diária do ar $\left({ }^{\circ} \mathrm{C}\right) ; \mathrm{Tb}$, a temperatura base $\left({ }^{\circ} \mathrm{C}\right) ; \mathrm{N}, \mathrm{o}$ número de dias, em cada fenofase. A equação usada somente quando $\mathrm{Tb}<\mathrm{Tn}$.

A temperatura-base adotada para o coqueiro foi de $15^{\circ} \mathrm{C}$ (Passos, 1994). 
Estimou-se a correlação entre as fases fenológicas por meio de experimento de parcelas subdivididas no tempo, segundo Steel \& Torrie (1960).

\section{Resultados e Discussão}

O climatograma no qual foram distribuídas as fases fenológicas é mostrado na Figura 1.

\section{Foliação}

Nas cultivares e no híbrido, a emissão de folhas foi detectada tanto no período seco (segunda quinzena de janeiro/96 à primeira semana de fevereiro/96; segunda semana de março à primeira semana de abril; segunda quinzena de setembro à primeira semana de outubro, e segunda quinzena de novembro a janeiro/97), quanto no período das chuvas (segunda semana de abril à primeira quinzena de setembro), embora no período das chuvas esta fase fenológica tenha sido mais freqüente (Tabela 1).

Cada espécime/cultivar produziu cerca de 11 folhas anualmente, e a disponibilidade de água no solo não influiu neste mecanismo. Dados semelhantes foram citados por Bondar (1955) e Child (1974), para quem o coqueiro emite uma a duas folhas num período de 30 dias, e estas podem permanecer vivas por um período de três anos a três anos e meio ou de um ano e meio a dois anos, conforme Gomes (1992). Segundo Passos (1994) em condições de estiagem prolongada, ocorre diminuição do fenorritmo foliar e redução da longevidade da folha, o que não ocorreu nas cultivares estudadas. Foi observado, ainda, que o início da abertura foliar se dá com 30 dias, podendo a abertura total ocorrer em até 90 dias.

A morte das folhas aconteceu durante todo o ano, e foi mais evidente no período compreendido entre a

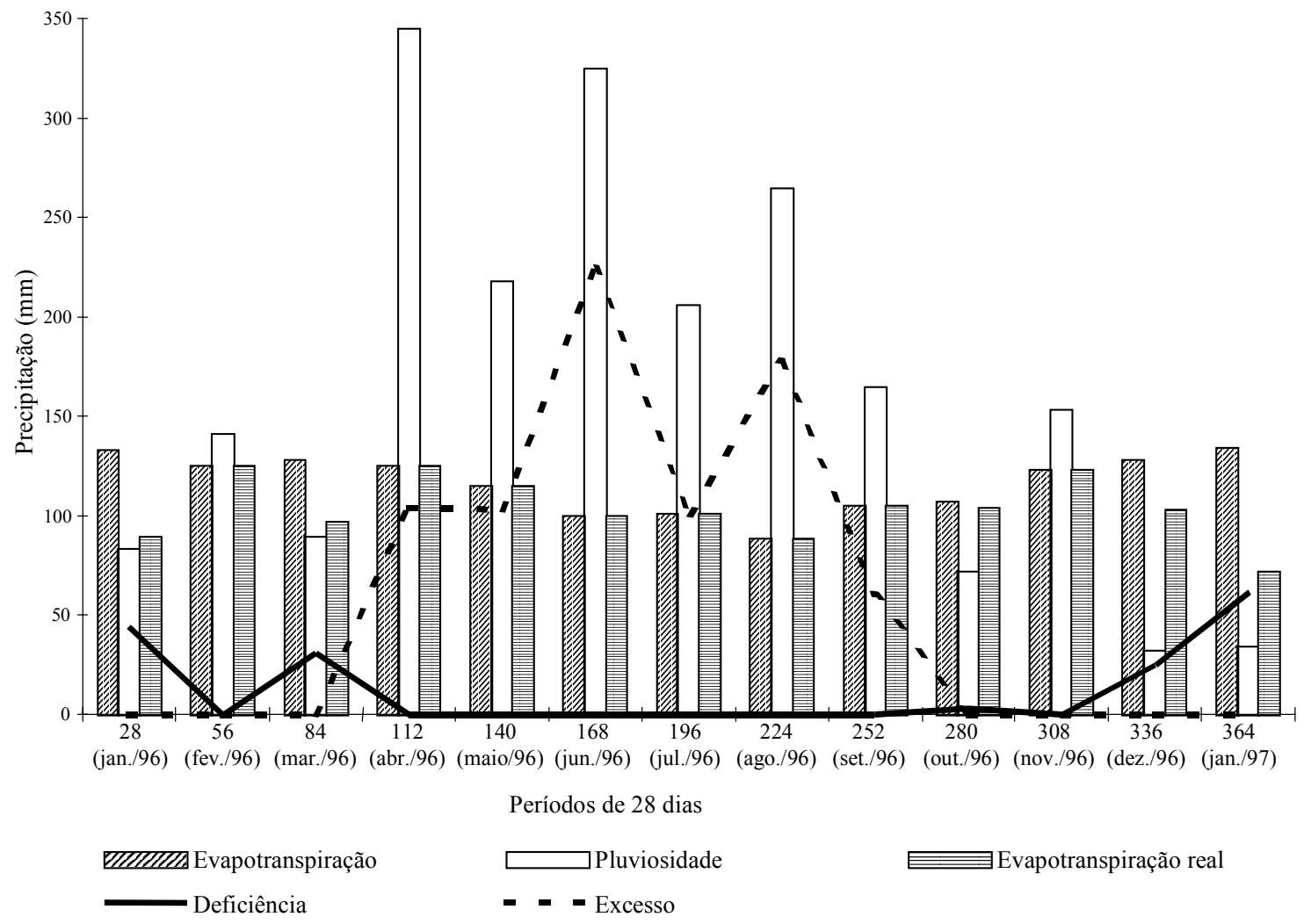

Figura 1. Climatograma resultante do balanço hídrico, segundo Thornthwaite \& Mather (1955), na Unidade de Execução de Pesquisa de Itapirema, Município de Goiana, PE. 


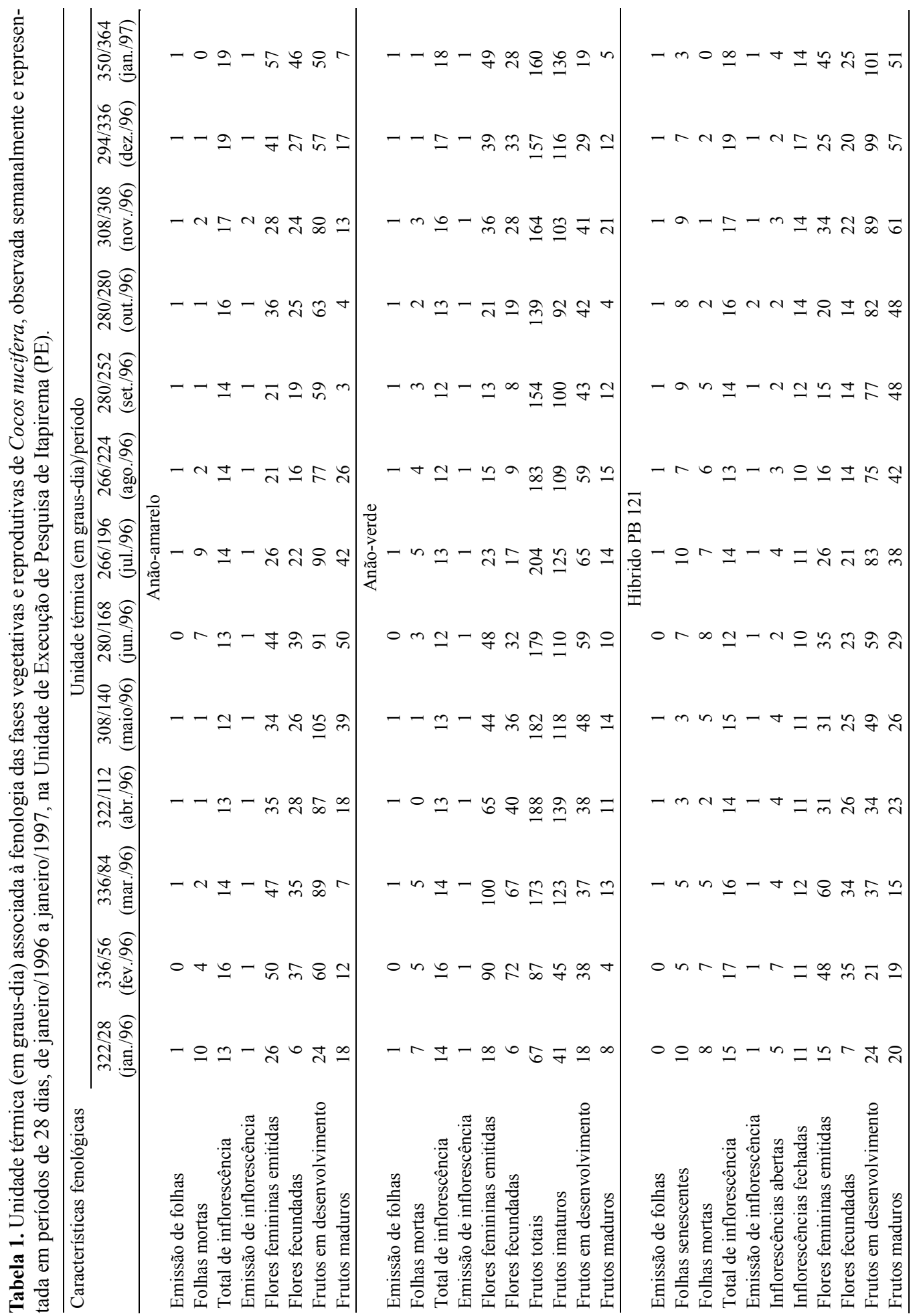


estação seca e as primeiras chuvas do ano (segunda quinzena de janeiro/96 à última semana de abril), e na época chuvosa, na qual foram detectados picos nas taxas de precipitações pluviais (primeira semana de junho à penúltima semana de agosto) (Tabela 1). Reduções no número de folhas mortas também foram verificadas tanto durante a estação chuvosa (segunda semana de abril à última semana de maio) quanto durante a segunda estação seca (segunda quinzena de setembro à primeira semana de janeiro/97). As cultivares perdem aproximadamente uma folha/mês, e esse número pode chegar, em média, a 20 folhas/ano, o que está de acordo com Bondar (1955).

\section{Floração}

O número total de inflorescências, que são axilares, foi semelhante tanto na estação seca como na chuvosa e verificaram-se dois picos: o primeiro, durante a primeira estação seca (segunda semana de fevereiro à primeira semana de março) até o início da estação chuvosa (segunda semana de abril à segunda semana de maio), e o segundo, do início ao final da segunda estação seca (segunda quinzena de setembro à primeira semana de janeiro/97) (Tabela 1). Durante a estação chuvosa (segunda semana de junho à primeira quinzena de setembro) houve uma pequena redução na produção de inflorescências, nas três cultivares. O coqueiro híbrido foi o que apresentou maior quantidade de inflorescências, perfazendo um total de 200, anualmente, enquanto nas cultivares Anão-amarelo e Anão-verde foi computado um total de 194 e 183 inflorescências, respectivamente. Na fase emissão de inflorescência ocorreram respostas estáveis de fenorritmo entre as plantas estudadas, da primeira à segunda estação seca, ou seja, durante todo o período de observação. Foram produzidas, em média, 14 inflorescências anuais, a cada intervalo de 28 dias (Tabela 1). Estes resultados estão de acordo com os obtidos por Bondar (1955) e Gomes (1992). As cultivares estudadas emitem uma inflorescência por mês, ocasionalmente duas (Anão-amarelo e híbrido), no período seco.

$\mathrm{O}$ quadrante na emissão de inflorescências foi predominantemente Sudeste nas duas cultivares e no híbrido PB 121 (Figura 2). Individualmente, não foi observada predominância de quadrante no coqueiro Anão-amarelo, e ocorreu uma distribuição heterogênea na emissão de inflorescências em todos os quadrantes. O quadrante dominante foi o Sudeste na cultivar Anão-verde e o Sudoeste no híbrido PB 121.

A determinação do quadrante predominante do vento foi considerada porque, tratando-se de uma cultura em condições de exploração comercial, serve para estimar a época da floração e permitir uma orientação espacial onde irá dominar a frutificação, e, conseqüentemente, influenciar na produção. Além disso, pode-se detectar o local de maior incidência dos visitantes florais, evitando, deste modo, afugentálos ou eliminá-los quando da aplicação de inseticidas contra pragas ou agentes patógenos, pois é preciso impedir que se perturbe o equilíbrio ambiental.

Registrou-se que a espata, desde a emissão, passa por um período de 11-12 semanas para se desenvolver e abrir-se, o que corresponde aos resultados descritos por Bondar (1955), Gomes (1992) e Pas$\operatorname{sos}(1994)$.

No presente estudo, as cultivares de Cocos nucifera floresceram regularmente durante todos os meses do ano, o que está de acordo com Reitz (1974).

O padrão de diferenciação básico entre flores femininas emitidas e fecundadas é o fato de que nas primeiras, sua cor confunde-se com a cor dos ramos do espádice, são menores que as flores fecundadas, e pode-se encontrar até $100 \%$ de flores masculinas inseridas nos escrobículos.

Constatou-se caducifloria tanto na estação seca quanto na chuvosa. Evidenciou-se, ainda, que após o primeiro pico de caducifloria houve aumento na floração, resultado, este, semelhante ao de estudo de Alvim (1966). Além disso, a interação entre fatores abióticos e bióticos podem, também, influenciar na floração (Alvim, 1966) e na relação planta-polinizadores-dispersores.

A abertura das flores femininas se deu com duas a três semanas após o rompimento da espata; sua maturação é progressiva, ocorrendo, no mesmo espádice, flores em diferentes estádios de desenvolvimento; as flores da base são as primeiras a serem fecundadas, o que está de acordo com Faria (1986).

$\mathrm{Na}$ espécie estudada, a floração é do tipo cornucópia, apresentando ritmos endógenos e sazonalidade entre suas cultivares. 


\section{Frutificação}

O coqueiro produziu, durante todo o ano, 15 a 16 cachos. Ocorreram frutos em diferentes estádios de desenvolvimento em um mesmo cacho, o que está de acordo com Bondar (1955).

Durante a fase de desenvolvimento do fruto, houve redução gradual no seu número, prolongando-se até a fase de maturação. Esse comportamento foi mais evidente no coqueiro Anão-verde, principalmente durante a época seca (Tabela 1).

A quantidade de frutos maduros, em relação à fase de desenvolvimento, teve uma redução, principalmente nas cultivares Anão-verde e Anão-amarelo, tanto no período seco, como no período chuvoso. Na cultivar Anão-amarelo houve acréscimo, e posterior diminuição, de frutos durante a estação chuvosa. No híbrido PB 121, ocorreu aumento deste fenorritmo a partir da estação chuvosa até a estação seca (Tabela 1).

\section{Índices de fecundação das flores e produção dos frutos}

A análise dos índices de fecundação das flores e produção dos frutos foi associada à fenologia e à sua relação com os fatores climáticos (Figura 3).

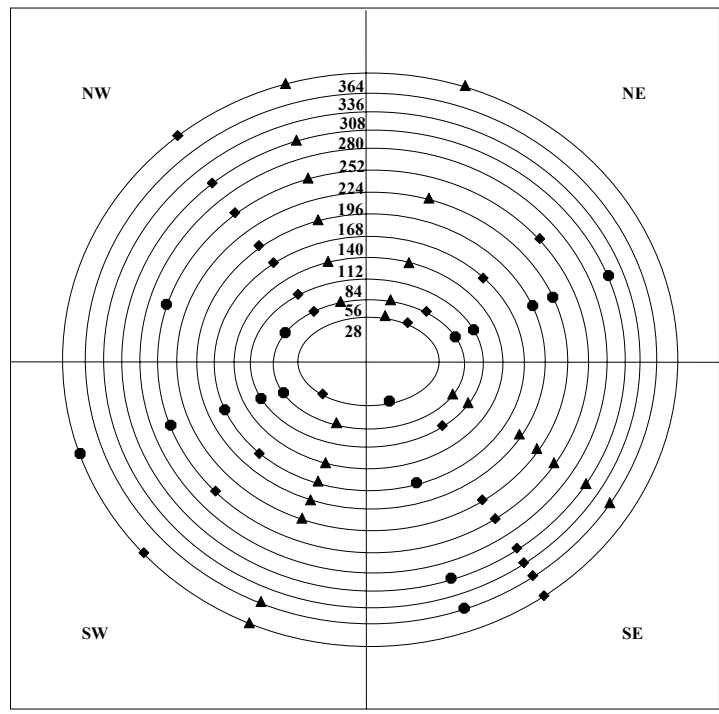

Figura 2. Variação do quadrante predominante na fenofase emissão de inflorescência, observada semanalmente e apresentada em períodos de 28 dias, em Cocos nucifera, cultivares Anão-amarelo $(\boldsymbol{\Delta})$ e Anão-verde $(\bullet)$ e híbrido PB 121 (๑), no período de janeiro/1996 a janeiro/1997.
A produção do coqueiro foi decorrente do número de frutos por espécime ou por hectare, anualmente. De acordo com Murray (1942), os fatores que determinam esta produção são: genético, climático, edáfico e manejo cultural.

Reduções periódicas ocorreram entre as cultivares na estação seca e início da chuvosa, as quais estão associadas tanto às adaptações intrínsecas dos coqueirais, quanto à coleta dos frutos nesta estação. Picos ocorreram durante a estação chuvosa, nas cultivares Anão-amarelo e Anão-verde, e, durante a estiagem, no híbrido PB 121. O índice de produção variou de $12 \%$ a $44 \%$, ambos na estação seca.

Constatou-se uma abscisão dos frutos desde a produção dos imaturos aos maduros, resultado este que está de acordo com o obtido por Murray (1942).

\section{Graus-dia}

Houve valores diferenciados na quantidade de graus-dia requerida para cada fase fenológica e cada cultivar de coqueiro, o que está de acordo com Maniero (1980) (Tabela 1).

Chandler Junior (1987) comenta que a fase vegetativa requer maior quantidade de graus-dia, indicando assim uma taxa ideal para o desenvolvimento da maioria das plantas. Nestas condições, o balanço hídrico revelou que, embora tenha infiltrado água no solo, a capacidade de água disponível não foi suficiente para promover a emissão de folhas, pois o coqueiro híbrido, por ser uma planta geneticamente melhorada, é mais exigente em quantidade de unidades térmicas, e é também o que sofre mais influência dos fatores ambientais, nesta fase. Tal comportamento se explica, também, pelo fato de que na estação seca se exige mais do coqueiral, em termos de produtividade, pois, como já foi citado, nesta época ocorre maior procura para o consumo do fruto in natura. A limpeza que é feita nas plantas após a coleta dos frutos e a aplicação de inseticidas contra pragas, por causa das condições de exploração comercial local, comprometem os estádios de desenvolvimento fisiológico das plantas.

Nas fases reprodutivas, os valores referentes aos graus-dia variaram em cada cultivar e no híbrido PB 121, nas mesmas fases fenológicas (Tabela 1).

A utilização de graus-dia associada à fenologia é importante para estimar o potencial de produção 

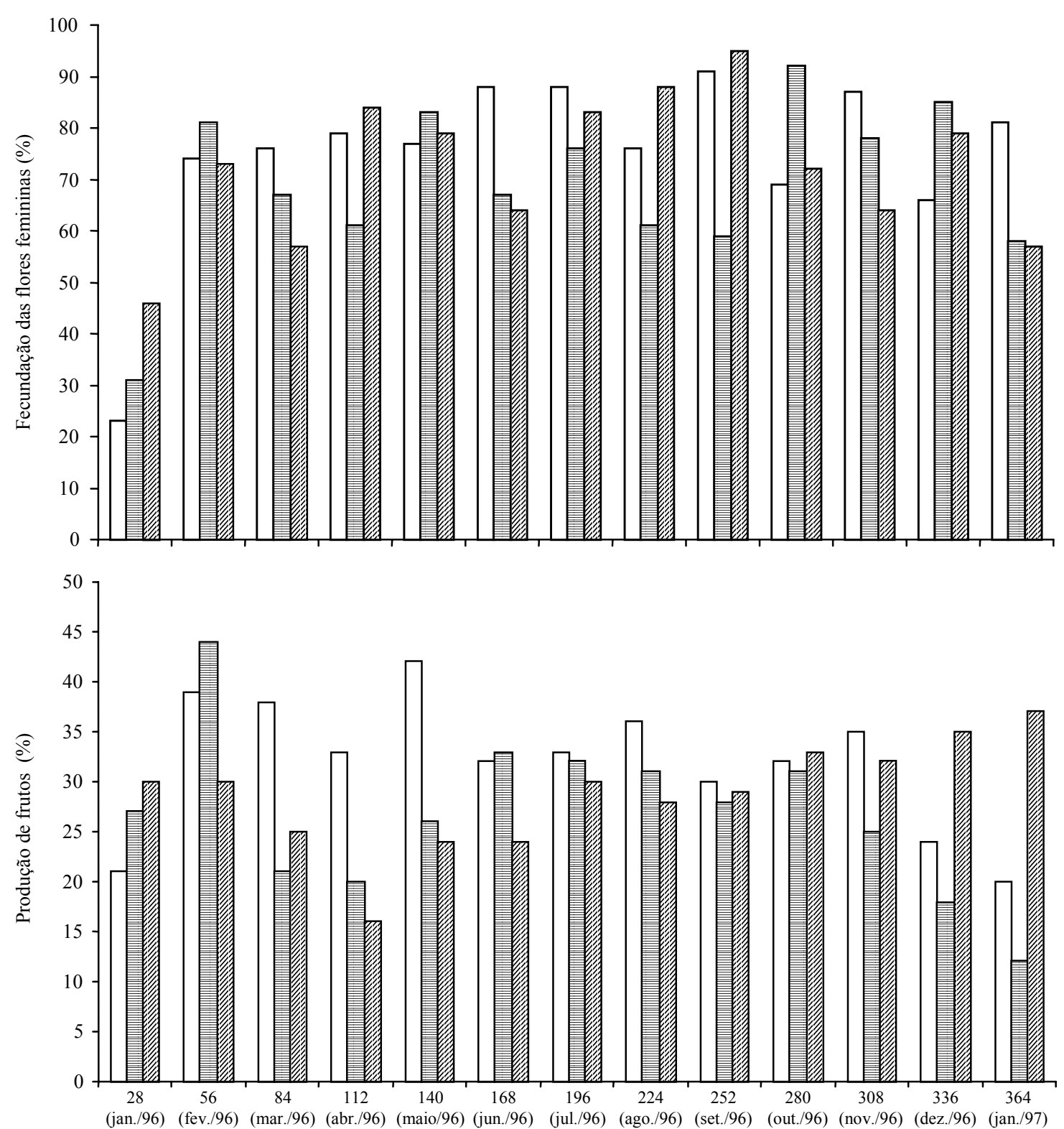

Período de 28 dias

Figura 3. Porcentagem de fecundação de flores femininas e de produção de frutos, nas cultivares Anão-amarelo ( $\square$ ) e Anão-verde (㢄) e no híbrido PB 121 (庭) de Cocos nucifera, observada semanalmente e apresentada em períodos de 28 dias, de janeiro/1996 a janeiro/1997.

vegetativa e reprodutiva de espécies de uma deter- na sua totalidade. Por isso, recomenda-se que este minada área ou região, nos diversos tipos de método seja aprimorado e correlacionado com ouecossistemas, embora o crescimento e desenvolvi- tros elementos, tais como: fatores edafoclimáticos, mento estejam associados aos fatores ambientais, visitantes florais, predadores e dispersores, pois es- 
tes fatores sofrem variações de acordo com as espécies, fases fenológicas e ecossistemas estudados, particularmente na região tropical.

\section{Conclusões}

1. Cada espécime/cultivar emite, em média, cerca de 11 folhas por ano, com valores variando entre 8 e 14 .

2. As cultivares e o híbrido PB 121 têm o mesmo número de inflorescências emitidas, mas não o mesmo número de inflorescências desenvolvidas, em razão da intensa caducifloria que ocorre durante o crescimento das respectivas inflorescências.

3. Os frutos apresentam diferentes estádios de desenvolvimento num mesmo espécime e cacho.

4. Na fase de emissão foliar são necessários, para as cultivares e para o híbrido PB 121, 1.540 graus-dia.

5. Para a realização da fase de floração, são necessários 3.640 graus-dia para a cultivar Anão-amarelo; 2.754 graus-dia para Anão-verde, e 3.304 grausdia para o híbrido PB 121.

6. Para a fase de frutificação, são necessários 3.794 graus-dia para a cultivar Anão-amarelo; 2.758 graus-dia para Anão-verde e 4.826 graus-dia para o híbrido PB 121.

\section{Referências}

ALVIM, P. T. Factors affecting flowering of the cocoa tree. Cocoa Growers Bulletin, Birmingham, v. 7, p. 15-19, 1966.

BELO, M. A. M. Observações sobre a floração de Acrocomia intumescens Drude (Palmae): II. Novas evidências de sua correlação com fatores climáticos. Recife: UFPE, $1989.40 \mathrm{p}$.

BONDAR, G. A cultura do coqueiro (Cocos nucifera) no Brasil. Salvador: Tipografia Naval, 1955. 91 p.

CHANDLER JUNIOR, R. F. An analysis of factors affecting rice yield. Newsletter, Taipei, v. 19, p. 23-41, 1987.

CHILD, R. Coconuts. London: Longman, 1974. 335 p.

EMPRESA PERNAMBUCANA DE PESQUISA AGROPECUÁRIA (Recife, PE). Projeto de mudas de coqueiro. Goiana, 1981. 17 p.

ENCARNAÇÃO, C. R. F. da. Observações meteorológicas e tipos climáticos das unidades e campos experimentais da Empresa Pernambucana de Pesquisa Agropecuária (IPA). Recife: IPA, 1979. 100 p.
FALCÃO, M. A. Aspectos fenológicos, ecológicos e de produtividade de alguns frutos cultivados na Amazônia. Manaus: Instituto de Pesquisa da Amazônia, 1979. v. 1.

FARIA, L. S. S. Botânica. In: CULTURA do coqueiro. Salvador: Seagri, 1986. 125 p.

FOURNIER, L. A. Un método cuantitativo para la medición de características fenológicas en árboles. Turrialba, San José, v. 24, n. 4, p. 422-424, 1974.

GOMES, R. P. O coqueiro-da-baía. 5. ed. São Paulo: Nobel, 1992. 111 p.

MANIERO, A. M. Aplicação do método de graus-dia em cana-de-açúcar (Saccharum spp.). 1980. 76 f. Dissertação (Mestrado) - Escola Superior de Agricultura Luiz de Queiroz, Piracicaba.

MORELlATO, L. P. C.; LEITÃO-FILHO, H. F.; RODRIGUES, R. R.; JOLY, C. A. Estratégias fenológicas de espécies arbóreas em floresta de altitude na Serra do Japí, Jundiaí, São Paulo. Revista Brasileira de Biologia, Rio de Janeiro, v. 50, n. 1, p. 149-162, 1990.

MURRAY, D. B. Coconut palm. Science, Washington, v. 95, p. 383-407, 1942.

NOVA, N. A. V.; PEDRO JÚNIOR, M. J.; PEREIRA, A. R.; OMETTO, J. C. Estimativa de graus-dia acumulados acima de qualquer temperatura base, em função das temperaturas máximas e mínimas. São Paulo: USP-Instituto de Geografia, 1972. 8 p. (Caderno de Ciência da Terra, 30).

OMETTO, J. C. Freqüência de irrigação em cana-deaçúcar. Piracicaba: Esalq, 1987.37 p.

PASSOS, E. E. M. Ecofisiologia do coqueiro. In: FERREIRA, J. M. S.; WARWICK, D. R. N.; SIQUEIRA, L. A. Cultura do coqueiro no Brasil. Aracaju: Embrapa-SPI, 1994. p. 75-81.

QUEIROZ, L. A. C. de; GALVÃO FILHO, F. B. de A.; SIQUEIRA, E. R. de. Caracterização de populações de coqueiros gigantes do Brasil no Rio Grande do Norte. Natal: Emparn, 1990. 12 p. (Boletim de Pesquisa, 17).

REITZ, R. Palmeiras. Itajaí: Herbário Barbosa Rodrigues, 1974. $189 \mathrm{p}$.

SIQUEIRA, L. A.; SIQUEIRA, E. R.; DANTAS, M. S. F.; REGO, G. M.; RIBEIRO, F. E. Avaliação do comportamento de coqueiros híbridos em Sergipe e norte da Bahia. Sergipe: Embrapa-CNPCo, 1992. 8 p. (Pesquisa em Andamento, 47).

STEEL, R. G. D.; TORRIE, J. H. Principles and procedures of statistics. Nova York: McGraw-Hill, 1960. 481 p.

THORNTWAITE, C. W.; MATHER, J. R. The water balance. Publications in Climatology, Centerton, v. 8, n. 1, p. 104, 1955. 